\title{
Language history questionnaire: A Web-based interface for bilingual research
}

\author{
PING LI, SARA SEPANSKI, and XIAOWEI ZHAO \\ University of Richmond, Richmond, Virginia
}

\begin{abstract}
A Web-based interface has been developed to facilitate researchers in collecting language history information online. Most researchers use their own versions of language history questionnaires for specific studies in second language acquisition. Although these versions of questionnaires all differ from one another in some respects, there is a significant amount of overlap between them. Here we identify the crucial dimensions that most investigators consider important to include in such a questionnaire. We have examined the most commonly asked questions in 41 published questionnaires, and on the basis of our analyses we propose a general L2 language history questionnaire. Subjects can enter some or all of the information on the Web, and the results are automatically generated as an RTF output file on the user's desktop.
\end{abstract}

It is common practice to use language history questionnaires in bilingualism or second language (L2) research as an important tool to assess L2 learners' linguistic proficiency. Many studies in the field use the outcomes from such assessments as independent variables to predict or for correlation with learners' linguistic performances derived from behavioral experiments. Although such questionnaires are important tools, researchers disagree as to what questions need to be asked of the learner in order to assess his/her language history in the two or more languages. Most researchers make up their own versions of history questionnaires for specific studies. These individual versions naturally differ in many respects, but there is also a significant amount of overlap between them. In particular, there are dimensions that most investigators consider crucial to include in a questionnaire of this sort. In the present article, we identify such crucial dimensions by examining the most commonly asked questions in published questionnaires, and on the basis of our analyses, we propose a generic language history questionnaire, intended to be accessible to the research community at large through a Web-based interface.

\section{Survey of Language History Questionnaires in Bilingual Research}

We surveyed a total of 41 published studies in the bilingual or L2 literature that have used language history

\footnotetext{
Preparation of this article was made possible by a grant from the $\mathrm{Na}$ tional Science Foundation (BCS-0131829) to P.L. S.S. was supported by a Graduate Research Grant from the University of Richmond, and she is now with the Department of Human Development, Cornell University. We thank François Grosjean, Gisela Jia, and Carmen Silva-Corvalan for helpful comments and suggestions. Please address correspondence to P. Li, Department of Psychology, University of Richmond, Richmond, VA 23173 (e-mail: pli@richmond.edu). This article should be cited as a reference in publications that make use of the questionnaire for collecting language history information.
}

questionnaires in some form (see all articles listed in the References section, except Bordens \& Abbott, 2005; Hair, Anderson, Tatham, \& Black, 1998; Hakuta, Bialystok, \& Wiley, 2003; Major, 2001; Sepanski, 2005; Sepanski \& Li, 2006). Articles were surveyed on the basis of their availability, with no particular exclusionary criterion. Some of the published questionnaires are detailed and informative (e.g., Liu, Bates, \& Li, 1992), whereas others are short and informal. Some studies include the complete questionnaire in an appendix, whereas others give a synopsis or a summary of the items used. The 10 most frequent questionnaire items, in order of frequency (excluding name, gender, and contact information), are the following.

1. Current age (in years; sometimes calculated from birthday).

2. Years of residence in the country where L 2 is spoken.

3. Age at which L2 learning started.

4. Self-assessment in reading ability in L1 and L2, separately.

5. Self-assessment in speaking ability in L1 and L2, separately.

6. Years of L2 instruction received.

7. Self-assessment in writing ability in L1 and L2, separately.

8. Language spoken at home.

9. Self-assessment in comprehension ability in L1 and L2, separately.

10. Native language.

Table 1 provides a summary of the questions or variables that have appeared in at least 3 of the 41 studies that we surveyed and the number of occurrences in these studies. It can be seen that the 10 most frequently asked questions are typically related to important theoretical constructs in L2 or bilingualism research, such as age of acquisition, length of stay, and L2 proficiency in reading, writing, comprehension, and speaking. These are the dimensions that most researchers consider important to be included in a language history questionnaire. 
Table 1

Summary of Variables/Questions in Language History Questionnaires Surveyed $(N=41)$

\begin{tabular}{|c|c|c|}
\hline Variables/Questions & $\begin{array}{l}\text { Number of } \\
\text { Occurrences }\end{array}$ & $\begin{array}{l}\text { Percentage of } \\
\text { Occurrences }\end{array}$ \\
\hline Current age (age) & 31 & 75.6 \\
\hline Years of residence (yrs_res) & 23 & 56.1 \\
\hline Age learned at (age_lrn) & 19 & 46.3 \\
\hline Reading ability (reading) & 17 & 41.5 \\
\hline Speaking ability (speaking) & 17 & 41.5 \\
\hline Years of language instruction (yrsinst) & 16 & 39.0 \\
\hline Writing ability (writing) & 15 & 36.6 \\
\hline Gender of subject (sex) & 13 & 31.7 \\
\hline Language spoken at home (lang_hom) & 13 & 31.7 \\
\hline Speech comprehension ability (underst) & 13 & 31.7 \\
\hline Native language (native_l) & 12 & 29.3 \\
\hline Language at school (lang_sch) & 8 & 19.5 \\
\hline Years in a foreign school (yrsforsc) & 8 & 19.5 \\
\hline Native country (nat_coun) & 7 & 17.1 \\
\hline List of known languages (list_lan) & 7 & 17.1 \\
\hline Number yrs speaking L2 (yrsspL2) & 6 & 14.6 \\
\hline L2 overall proficiency (L2_prof) & 6 & 14.6 \\
\hline Age of arrival/immersion (aoa) & 6 & 14.6 \\
\hline$\%$ daily use of L2 (useofL 2 ) & 5 & 12.2 \\
\hline$\%$ daily use of L1 (useofL1) & 5 & 12.2 \\
\hline Preferred language (preferred) & 5 & 12.2 \\
\hline Setting of acquisition (setting) & 5 & 12.2 \\
\hline Status of immersion (immersio) & 5 & 12.2 \\
\hline Language used when socializing (lang_soc) & 5 & 12.2 \\
\hline Travel to L2 country (travel) & 5 & 12.2 \\
\hline Reading dominance (dominrea) & 4 & 9.8 \\
\hline Speaking dominance (dominsp) & 4 & 9.8 \\
\hline Understanding dominance (dominund) & 4 & 9.8 \\
\hline Writing dominance (dominwr) & 4 & 9.8 \\
\hline Hrs/day of radio/tv in L2 (rad_tvL2) & 4 & 9.8 \\
\hline Language(s) parents speak (lang_par) & 3 & 7.3 \\
\hline Years reading L2 (yrsrdL2) & 3 & 7.3 \\
\hline Frequency of speaking L1 at home (L1home) & 3 & 7.3 \\
\hline Frequency of speaking L1 at work (L1work) & 3 & 7.3 \\
\hline Frequency of speaking L1 w/friends (L1friend) & 3 & 7.3 \\
\hline
\end{tabular}

Note-The codes in parentheses are abbreviated variable names used in our data file.

A detailed examination of Table 1 shows that some less frequently occurring items may be related to the dimensions above as well. For example, age of arrival in the target L2 country, though less frequently used, is often linked to age at which L2 learning starts, and for some L2 learners, these two questions may be identical. Similarly, number of years speaking $L 2$ is often related to number of years of residence in the L2 country, and languages parents speak is often related to language spoken at home. A small number of questionnaires also assess the dominance of the participant's L1 versus L2, in terms of reading, writing, speaking, and comprehension. Finally, a large number of questions address the environment and usage of the two languages, including language of schooling, languages parents speak, percentage of time for L2 use daily, hours per day spent listening to radio or watching TV in L2, and language used when socializing.

\section{An Online Language History Questionnaire}

On the basis of our analyses above, we propose a general version of language history questionnaire, in a form that is easily accessible to L2 or bilingual researchers on the World-Wide Web: cogsci.richmond.edu/questionnaire/ main.html. The Web site allows users to enter their data in a user-friendly environment (including flexible menu options), and it automatically saves the output as an RTF file (see more details below). The interface currently works optimally with Internet Explorer (Version 6.0 or above), Netscape (Version 7.0 or above), or Mozilla Firefox. The complete text form is appended here in the Appendix, and it can be retrieved as a Word document from the Web site for paper-and-pencil completion if so desired.

At the beginning of the questionnaire is the contact information of the participant (Name, e-mail address, and telephone number). ${ }^{1}$ After these, the questionnaire has three main parts. Part A of the questionnaire includes some general questions (Items 1-12) related to the participant's language history, following the design principles for questionnaires or surveys (Bordens \& Abbott, 2005). These include current age, gender, education, age of L2 learning, years of residence, and length of L2 learning. Most important, Items 10 and 11 assess the participant's proficiency in each language in terms of reading, writing, speaking, and listening abilities, and the age and length of learning 
in these four domains. Note that questions in this part are the ones that have occurred most frequently in our survey of published questionnaires. ${ }^{2}$ We have added one question toward the end of this part with respect to the perceived accent of the participant, because foreign accent has been an important topic in L2 acquisition research (see Major, 2001, for a review). Thus, Part A of the questionnaire can be used by researchers who wish to conduct a general and relatively simple survey of the L2 learner's language background. Figure 1 presents a snapshot of the online questionnaire up to Item 4.

Part B of the questionnaire includes questions that are more specifically targeted to the language environment and language usage of the bilingual learner. These questions can be divided into three groups. The first group (Items 13-17) is related to the learner's language environment at home and in school (e.g., language used with parents). The second group of questions (Items 18-21) has to do with language use, including percentage of time using L1 or L2, such as hours per day spent watching TV or listening to radio in L1 versus L2, hours per day reading newspapers, magazines, or other materials in L1 or L2, and hours per day using L1 or L2 in work- or studyrelated activities. Finally, the third group of questions (Items 22-29) is related to participants' specific bilingual habits (such as language used in dreaming and counting, and language mixing habits) and language dominance or language preferences in different linguistic and social settings. This group also includes some other miscellaneous questions concerning linguistic experiences (e.g., residence in foreign countries). Here participants may also provide their scores from standardized proficiency tests (e.g., TOEFL, GRE, IELTS, SAT-II, et al.), because these scores can be used to index the learner's overall L2 ability.
Given the specific nature of the questions in this part, researchers may require the participant to answer only some of the questions for their specific research purposes. Figure 2 presents a snapshot of Part B of the questionnaire.

Part $\mathrm{C}$ of the questionnaire gives researchers or users the freedom to customize the online questionnaire by adding their own questions for their specific study needs. Users can type in the questions and the answers on the open-ended dialogue boxes.

Finally, when the participants complete all questions that are required by the research, they scroll down to the end of the Web page and hit the Submit button. An RTF file that includes all the information provided by participants is automatically generated and saved on the user's desktop. The name of the file will be the participant's name (if provided) plus the IP address of the computer used, with a file extension .rtf. The participant or the researcher can open the file within Word for further modification or analysis. Figure 3 presents an example of the RTF output file (Part A), in which the individual questions and corresponding answers are itemized and recorded.

\section{Validity and Reliability}

Because our online language history questionnaire is based on question items that have been used by many researchers in previous studies, a certain degree of validity (both construct validity and content validity) can be assumed from the start. However, in order to assess predictive validity of the measure, we administered our generic questionnaire (both Part A and Part B) to 40 EnglishSpanish bilinguals at the University of Richmond as part of a larger research project (Sepanski, 2005). Although it is beyond the scope of this technical report to provide the details of our analyses (see Sepanski, 2005, and Sepanski

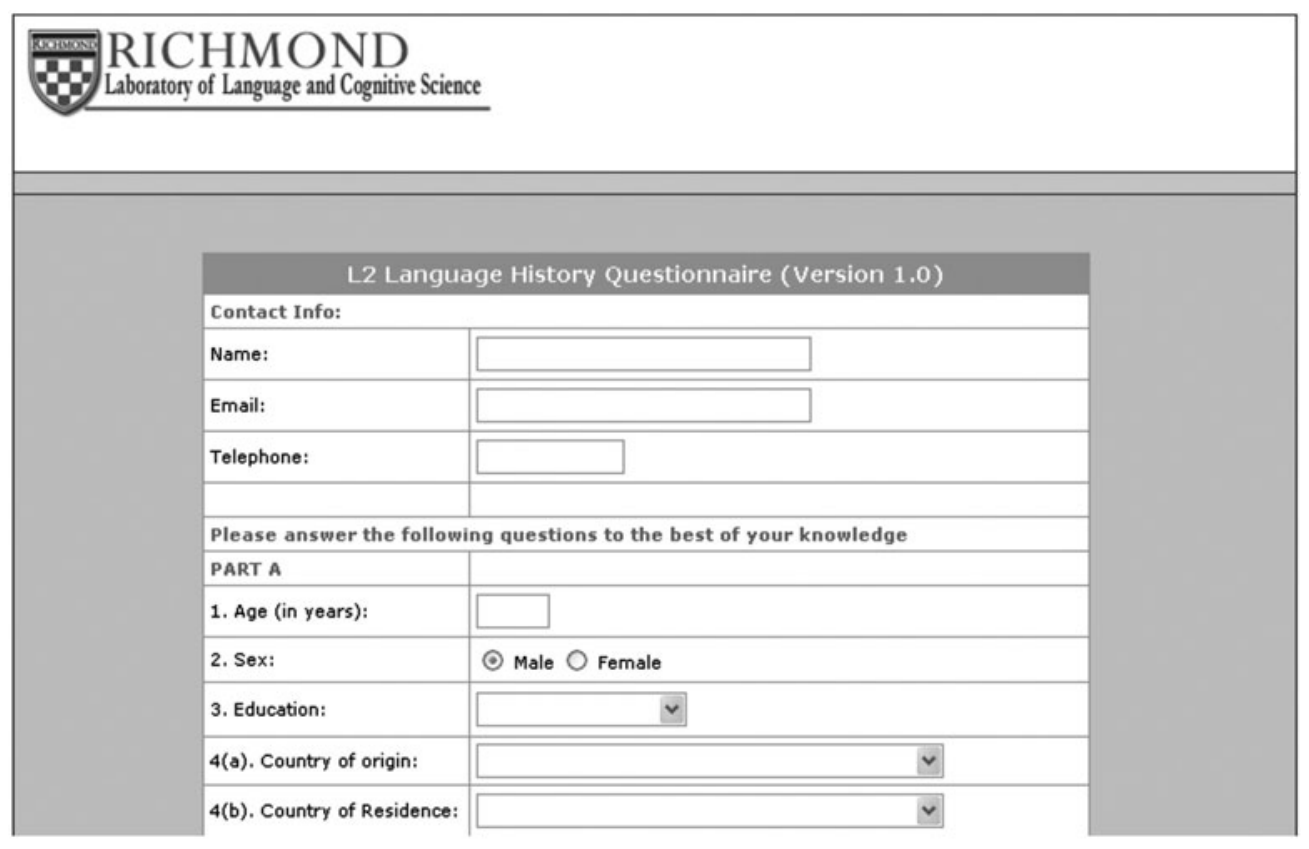

Figure 1. A portion of the online questionnaire (Part A). 


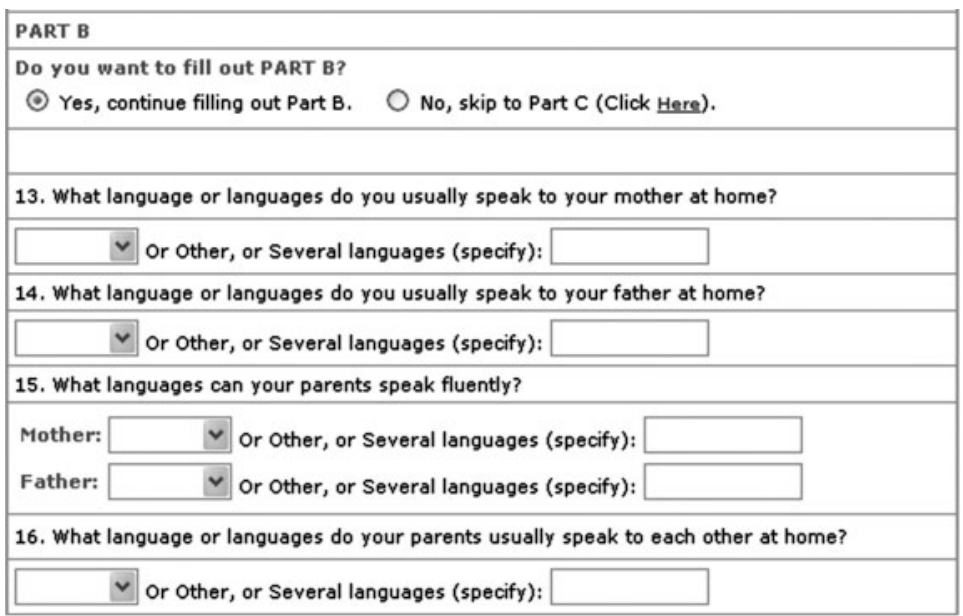

Figure 2. A portion of the online questionnaire (Part B).

\& Li, 2006, for details), we have tested the validity and reliability of the questionnaire in a number of ways: (1) a bivariate correlation analysis indicating significant correlations between theoretically important constructs (e.g., age of acquisition, years of learning, amount of L2 use) and self-assessed reading, speaking, and comprehension abilities from the questionnaire; (2) an aggregate score determined by a participant's answers to all questions predicting the participant's overall L2 proficiency; (3) a discriminant analysis and a multiple regression analysis (including an analysis with the participant's SAT-II scores in Spanish as the criterion variable) showing that our questionnaire can successfully separate participants into three proficiency groups (low, intermediate, and high); and

L2 Questionnaire 1

L2 Language History Questionnaire

Date: January 16, 2006

Contact Info:

Name: Thomas Wang

Email: wangt@richmond.edu

Telephone: 804-287-1234

Please answer the following questions to the best of your knowledge:

Part A:

1. Age: 30 years old

2. Sex: Male

3. Education: $\mathrm{PhD}$

4(a). Country of Origin: China, People's Republic

4(b). Country of Residence: United States

5. Your country of origin and country of residence are different, then how long have you

been in the country of your current residence?

10 years.

Figure 3. A sample RTF output file (Part A). 
(4) a split-half reliability test on the quantitative variables of the questionnaire (Hair et al., 1998) indicating high reliability (with the split-half coefficient at .85). We believe that use of the online questionnaire by researchers in the field will help to further validate this questionnaire and make it more reliable.

\section{Conclusions}

If each researcher makes up his or her own language history questionnaire, we will end up with as many questionnaires as there are researchers. Given that there are significant overlaps between different versions of existing questionnaires, we have proposed a general L2 language history questionnaire that includes question items that most investigators consider crucial. To further facilitate the ease of data collection with this general questionnaire, we have developed a user-friendly Web-based interface, freely available on the World-Wide Web.

The current version of the questionnaire is Version 1. Future developments of the online questionnaire (Version 2) will include (1) the addition of help pages linked to some specific question items; (2) the implementation of automatic calculation of an overall aggregate score for each participant, given that such a score may be useful to the assessment of the bilingual learner's overall proficiency (Sepanski \& Li, 2006); (3) the implementation of the option that allows the user to submit the questionnaire results (the RTF file) to the investigator via e-mail; and (4) an enhanced Part $\mathrm{C}$, in which the user-selected questions can dynamically pop up on the Web. With anticipated widespread use, we hope to further refine the questionnaire (Version X), and to create an international database of L2 language background and history with potential consortium agreements from bilingual researchers worldwide.

\section{REFERENCES}

Altarriba, J. (2003). Does cariño equal "liking"? A theoretical approach to conceptual nonequivalence between languages. International Journal of Bilingualism, 7, 305-322.

BAhrick, H. P., HAll, L. K., Goggin, J. P., BAhrick, L. E., \& Berger, S. A. (1994). Fifty years of language maintenance and language dominance in bilingual Hispanic immigrants. Journal of Experimental Psychology: General, 123, 264-283.

BialystoK, E., \& Miller, B. (1999). The problem of age in secondlanguage acquisition: Influences from language, structure, and task. Bilingualism: Language \& Cognition, 2, 127-145.

BoRdENS, K. S., \& Аввотт, B. B. (2005). Research design and methods: A process approach (6th ed.). Boston: McGraw-Hill.

Brown, C. A. (1998). The role of the L1 grammar in the L2 acquisition of segmental structure. Second Language Research, 14, 136-193.

Chee, M. W. L., TAN, E. W. L., \& ThIEL, T. (1999). Mandarin and English single word processing studied with functional magnetic resonance imaging. Journal of Neuroscience, 19, 3050-3056.

Costa, A., \& Caramazza, A. (1999). Is lexical selection in bilingual speech production language-specific? Further evidence from SpanishEnglish and English-Spanish bilinguals. Bilingualism: Language \& Cognition, 2, 231-244.

Costa, A., Kovacic, D., Franck, J., \& Caramazza, A. (2003). On the autonomy of the grammatical gender systems of the two languages of a bilingual. Bilingualism: Language \& Cognition, 6, 181-200.

Costa, A., \& Santesteban, M. (2004). Lexical access in bilingual speech production: Evidence from language switching in highly proficient bilinguals and L2 learners. Journal of Memory \& Language, 50, 491-511.
Derwing, T. M., Rossiter, M. J., Munro, M. J., \& Thomson, R. I. (2004). Second language fluency: Judgments on different tasks. Language Learning, 54, 655-679.

FÉLIX-BRASDEFER, J. C. (2004). Interlanguage refusals: Linguistic politeness and length of residence in the target community. Language Learning, 54, 587-653.

Flege, J. E., \& MacKay, I. R. A. (2004). Perceiving vowels in a second language. Studies in Second Language Acquisition, 26, 1-34.

Gollan, T. H., \& Acenas, L.-A. R. (2004). What is TOT: Cognate and translation effects on tip-of-the-tongue states in Spanish-English and Tagalog-English bilinguals. Journal of Experimental Psychology: Learning, Memory, \& Cognition, 30, 246-269.

Gollan, T. H., Montoya, R. I., \& Werner, G. A. (2002). Semantic and letter fluency in Spanish-English bilinguals. Neuropsychology, 16, 562-576.

Gollan, T. H., \& Silverberg, N. B. (2001). Tip-of-the-tongue states in Hebrew-English bilinguals. Bilingualism: Language \& Cognition, 4, 63-83.

Grosjean, F. (1998). Studying bilinguals: Methodological and conceptual issues. Bilingualism: Language \& Cognition, 1, 131-149.

Hair, J. F., ANderson, R. E., Tatham, R. L., \& Black, W. C. (1998). Multivariate data analysis (5th ed.). Upper Saddle River, NJ: Prentice Hall.

Hakuta, K., Bialystok, E., \& Wiley, E. (2003). Critical evidence: A test of the critical-period hypothesis for second-language acquisition. Psychological Science, 14, 31-38.

HamiLton, R. (1998). Underdetermined binding of reflexives by adult Japanese-speaking learners of English. Second Language Research, 14, 292-320.

Hancin-Bhatt, B. (2000). Optimality in second language phonology: Codas in Thai ESL. Second Language Research, 16, 201-232.

Hermans, D. (2004). Between-language identity effects in picture-word interference tasks: A challenge for language-nonspecific or languagespecific models of lexical access? International Journal of Bilingualism, 8, 115-126.

Hermans, D., Bongaerts, T., De Bot, K., \& Schreuder, R. (1998). Producing words in a foreign language: Can speakers prevent interference from their first language? Bilingualism: Language \& Cognition, 1, 213-229.

JARED, D., \& KRoLL, J. F. (2001). Do bilinguals activate phonological representations in one or both of their languages when naming words? Journal of Memory \& Language, 44, 2-31.

JARED, D., \& Szucs, C. (2002). Phonological activation in bilinguals: Evidence from interlingual homograph naming. Bilingualism: Language \& Cognition, 5, 225-239.

JiA, G., AARONSON, D., \& WU, Y. H. (2002). Long-term language attainment of bilingual immigrants: Predictive factors and language group differences. Applied Psycholinguistics, 23, 599-621.

Kim, K. H. S., Relkin, N. R., LeE, K.-M., \& HiRsch, J. (1997). Distinct cortical areas associated with native and second languages. Nature, 388, 171-174.

Kroll, J. F., Michael, E., Tokowicz, N., \& Dufour, R. (2002). The development of lexical fluency in a second language. Second Language Research, 18, 137-171.

Lin, Y. H. (2001). Syllable simplification strategies: A stylistic perspective. Language Learning, 51, 681-718.

LiU, H., BATES, E., \& Li, P. (1992). Sentence interpretation in bilingual speakers of English and Chinese. Applied Psycholinguistics, 13, 451484.

Loebell, H., \& Bock, K. (2003). Structural priming across languages. Linguistics, 41, 791-824.

MAJOR, R. C. (2001). Foreign accent: The ontogeny and phylogeny of second language phonology. Mahwah, NJ: Erlbaum.

Malt, B. C., \& Sloman, S. A. (2003). Linguistic diversity and object naming by non-native speakers of English. Bilingualism: Language \& Cognition, 6, 47-67.

Marian, V., \& Spivey, M. (2003). Competing activation in bilingual language processing: Within- and between-language competition. Bilingualism: Language \& Cognition, 6, 97-115.

Masgoret, A.-M., \& GARDNER, R. C. (1999). A causal model of Spanish immigrant adaptation in Canada. Journal of Multilingual \& Multicultural Development, 20, 216-232.

Meador, D., Flege, J. E., \& MacKay, I. R. A. (2000). Factors affecting 
the recognition of words in a second language. Bilingualism: Language \& Cognition, 3, 55-67.

MonTrul, S. (2002). Incomplete acquisition and attrition of Spanish tense/aspect distinctions in adult bilinguals. Bilingualism: Language \& Cognition, 5, 39-68.

PAPP, S. (2000). Stable and developmental optionality in native and nonnative Hungarian grammars. Second Language Research, 16, 173-200.

Portin, M., \& Laine, M. (2001). Processing cost associated with inflectional morphology in bilingual speakers. Bilingualism: Language \& Cognition, 4, 55-62.

SAFANT JoRdÀ, M. P. (2003). Metapragmatic awareness and pragmatic production of third language learners of English: A focus on request act realizations. International Journal of Bilingualism, 7, 43-69.

SEPANSKI, S. E. (2005). Sentence recognition in native and foreign languages: Comprehension of form and meaning. Unpublished MA thesis, University of Richmond.

SEPANSKI, S. E., \& LI, P. (2006). Validation of a generic language history questionnaire for $L 2$ research. Unpublished manuscript, University of Richmond.

Silverberg, S., \& Samuel, A. G. (2004). The effect of age of second language acquisition on the representation and processing of second language words. Journal of Memory \& Language, 51, 381-398.

Snellings, P., van Gelderen, A., \& DE GlOPPER, K. (2002). Lexical retrieval: An aspect of fluent second language production that can be enhanced. Language Learning, 52, 723-754.

Tokowicz, N., Michael, E. B., \& Kroll, J. F. (2004). The roles of study-abroad experience and working-memory capacity in the types of errors made during translation. Bilingualism: Language \& Cognition, 7, 255-272.

Weber-Fox, C. M., \& Neville, H. J. (1996). Maturational constraints on functional specializations for language processing: ERP and behavioral evidence in bilingual speakers. Journal of Cognitive Neuroscience, $\mathbf{8}, 231-257$.

YING, H. G. (1999). Access to UG and language transfer: A study of L2 learners' interpretation of reconstruction in Chinese. Second Language Research, 15, 41-72.

YUAN, B. (1998). Interpretation of binding and orientation of the Chinese reflexive ziji by English and Japanese speakers. Second Language Research, 14, 324-340.

\section{NOTES}

1. To ensure the participant's anonymity, the researcher may ask the participant to leave specific contact info fields empty (or to simply type an identification number under Name). Our Web interface does not enforce this policy, and it is up to the researcher to decide whether names and contact information should be collected.

2. We have added Education in this part even though it is not a most frequently asked question (see Table 1), because research has shown a strong correlation between levels of education and second language proficiency (Hakuta et al., 2003).

\section{APPENDIX \\ L2 Language History Questionnaire (Version 1.0)}

Contact Information:

Name:

Telephone:

Email:

Today's Date:

Please answer the following questions to the best of your knowledge.

PART A

1. Age (in years):

2. Sex (circle one): Male/Female

3. Education (degree obtained or school level attended):

4(a). Country of origin:

4(b). Country of Residence:

5. If 4(a) and 4(b) are the same, how long have you lived in a foreign country where your second language is spoken? If 4(a) and 4(b) are different, how long have you been in the country of your current residence?

6 . What is your native language? (If you grew up with more than one language, please specify)

7. Do you speak a second language?

YES my second language is

NO (If you answered NO, you need not to continue this form)

8. If you answered YES to question 6(b), please specify the age at which you started to learn your second language in the following situations (write age next to any situation that applies).

At home

In school

After arriving in the second language speaking country

9. How did you learn your second language up to this point? (check all that apply)

Mainly through formal classroom instruction

Mainly through interacting with people

A mixture of both

Other (specify) 


\section{APPENDIX (Continued)}

10. List all foreign languages you know in order of most proficient to least proficient. Rate your ability on the following aspects in each language. Please rate according to the following scale (write down the number in the table):
very poor
poor
fair
functional
good
very good
native-like
1
2
3 4
5
7

\begin{tabular}{|l|l|l|l|l|}
\hline Language & $\begin{array}{l}\text { Reading } \\
\text { proficiency }\end{array}$ & $\begin{array}{l}\text { Writing } \\
\text { proficiency }\end{array}$ & $\begin{array}{l}\text { Speaking } \\
\text { fluency }\end{array}$ & $\begin{array}{l}\text { Listening } \\
\text { ability }\end{array}$ \\
\hline & & & & \\
\hline & & & & \\
\hline & & & & \\
\hline
\end{tabular}

11. Provide the age at which you were first exposed to each foreign language in terms of speaking, reading, and writing and the number of years you have spent on learning each language.

\begin{tabular}{|l|l|l|l|l|}
\hline \multirow{2}{*}{ Language } & \multicolumn{3}{|c|}{$\begin{array}{c}\text { Age first exposed } \\
\text { to the language }\end{array}$} & \multirow{2}{*}{$\begin{array}{c}\text { Number of } \\
\text { years learning }\end{array}$} \\
\cline { 2 - 4 } & Speaking & Reading & Writing & \\
\hline & & & & \\
\hline & & & & \\
\hline & & & & \\
\hline
\end{tabular}

12. Do you have a foreign accent in the languages you speak? If so, please rate the strength of your accent on a scale from 1 (not much of an accent) to 7 (very strong accent).

\begin{tabular}{|c|c|c|c|}
\hline \multirow[t]{2}{*}{ Language } & \multicolumn{2}{|c|}{$\begin{array}{c}\text { Accent } \\
\text { (circle one) }\end{array}$} & \multirow[t]{2}{*}{ Strength } \\
\hline & $\mathrm{Y}$ & $\mathrm{N}$ & \\
\hline & $\mathrm{Y}$ & $\mathrm{N}$ & \\
\hline & $\mathrm{Y}$ & $\mathrm{N}$ & \\
\hline
\end{tabular}

\section{PART B}

13. What language do you usually speak to your mother at home? (If not applicable for any reason, write N/A)

14. What language do you usually speak to your father at home? (If not applicable for any reason, write N/A)

15. What languages can your parents speak fluently? (If not applicable for any reason, write N/A)

Mother:

Father:

16. What language or languages do your parents usually speak to each other at home? (If not applicable for any reason, write N/A)

17. Write down the name of the language in which you received instruction in school, for each schooling level:

Primary/Elementary School

Secondary/Middle School

High School

College/University

18. Estimate, in terms of percentages, how often you use your native language and other languages per day (in all daily activities combined):
Native language
Second language
Other languages $\%$ $\%$
(Total should equal $100 \%$ )
$\%$ (specify: 


\section{APPENDIX (Continued)}

19. Estimate, in terms of hours per day, how often you watch TV or listen to radio in your native language and other languages per day.

Native language (hrs)

Second language (hrs)

Other languages (specify the languages and hrs)

20. Estimate, in terms of hours per day, how often you read newspapers, magazines, and other general reading materials in your native language and other languages per day.

Native language

Second language (hrs)

Other languages (hrs)

(specify the languages and hrs)

21. Estimate, in terms of hours per day, how often you use your native language and other languages per day for work or study related activities (e.g., going to classes, writing papers, talking to colleagues, classmates, or peers).

Native language (hrs)

Second language (hrs)

Other languages (specify the languages and hrs)

22. In which languages do you usually:

Add, multiply, and do simple arithmetic?

Dream?

Express anger or affection?

23. When you are speaking, do you ever mix words or sentences from the two or more languages you know? (If no, skip to question 25 ).

24. List the languages that you mix and rate the frequency of mixing in normal conversation with the following people, on a scale from 1 (mixing is very rare) to 5 (mixing is very frequent). Write down the number in the box.

\begin{tabular}{|l|l|l|}
\hline Relationship & Languages mixed & Frequency of mixing \\
\hline Spouse/family members & & \\
\hline Friends & & \\
\hline Co-workers & & \\
\hline
\end{tabular}

25. In which language (among your best two languages) do you feel you usually do better? Write the name of the language under each condition.
At home
At work

Reading

Writing

Speaking

Understanding

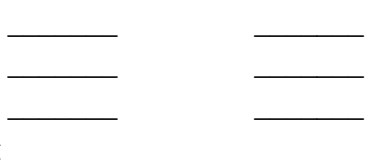

26. Among the languages you know, which language is the one that you would prefer to use in these situations?

At home

At work

At a party

In general

27. If you have lived or travelled in other countries for more than three months, please indicate the name(s) of the country or countries, your length of stay, and the language(s) you learned or tried to learn.

28. If you have taken a standardized test of proficiency for languages other than your native language (e.g., TOEFL or Test of English as a Foreign Language), please indicate the scores you received for each.
Language
Scores
Name of the Test
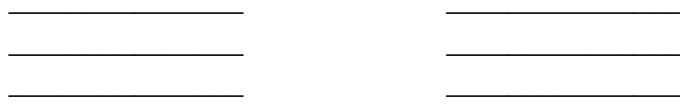

29. If there is anything else that you feel is interesting or important about your language background or language use, please comment below. 


\section{APPENDIX (Continued)}

PART C

(Do you have additional questions that you feel are not included above? If yes, please write down your questions and answers on separate sheets.)

(Manuscript received November 16, 2005; revision accepted for publication December 22, 2005. ) 